\title{
Postasphyxial Increases in Prostanoids in Cerebrospinal Fluid of Piglets
}

\author{
MASSROOR POURCYROUS, CHARLES LEFFLER, AND DAVID BUSIJA \\ Departments of Pediatrics [M.P.], Physiology and Biophysics [C.L., D.B.], University of Tennessee-Memphis, \\ Memphis, Tennessee 38163
}

\begin{abstract}
The dilator stimuli that contribute to postasphyxial increases in cerebral blood flow in the neonate are unclear. To assess the possible role of cyclooxygenase products in these responses, we measured pial arteriolar diameter in six piglets and determined levels of prostaglandin (PG) $E_{2}$ and 6-keto-PG $F_{1 \alpha}$ (hydrolysis product of $\mathrm{PGI}_{2}$ ) in cerebrospinal fluid (CSF) bathing the parietal cortex during control conditions, after 4-10 min of complete respiratory arrest (asphyxia), and after 5-12 min of reventilation. Pial arterioles are important resistance vessels in the cerebral circulation. Baseline pial arteriolar diameter was $220 \pm 40 \mu \mathrm{m}$ (mean \pm SEM) and increased to a maximum of $252 \pm 49$ and $267 \pm 56 \mu \mathrm{m}$ after asphyxia and reventilation, respectively. During control conditions, $\mathrm{CSF} \mathrm{PGE}_{2}(n=6)$ and 6-keto-PGF $1 \alpha(n=4)$ levels were $1947 \pm 310$ and $794 \pm 147 \mathrm{pg} / \mathrm{ml}$, respectively. During asphyxia, CSF levels of $\mathrm{PGE}_{2}$ did not increase, whereas 6keto-PGF ${ }_{1 \alpha}$ increased modestly. During reventilation, CSF $\mathrm{PGE}_{2}$ increased to $3576 \pm 499 \mathrm{pg} / \mathrm{ml}$, and 6-keto-PGF ${ }_{1 \alpha}$ increased to $2846 \pm 123 \mathrm{pg} / \mathrm{ml}$. In other experiments, we determined that these CSF levels of $\mathrm{PGE}_{2}$ and $\mathrm{PGI}_{2}$ (as 6keto-PGF $1 \alpha$ ) were within the vasodilator range for pial arterioles. We conclude that postasphyxial increases in pial arteriolar diameter are associated with a rise in CSF levels of dilator prostanoids. (Pediatr Res 24: 229-232, 1988)
\end{abstract}

\section{Abbreviations}

$\mathrm{PGE}_{2}$, prostaglandin $\mathrm{E}_{2}$

6-keto-PG $\mathrm{F}_{1 \alpha}$, 6-keto-prostaglandin $\mathrm{F}_{1 \alpha}$

CSF, cerebrospinal fluid

CBF, cerebral blood flow

$\mathbf{P G I}_{2}$, prostaglandin $\mathbf{I}_{2}$

Birth asphyxia and postnatal apneic episodes and their consequences are major concerns of physicians. While it is clear that $\mathrm{CBF}$ increases dramatically during and after asphyxia (1-3), the mechanisms underlying cerebrovascular dilation are poorly understood. Several mechanisms, including cerebral acidosis or accumulation of vasodilator metabolites such as prostanoids or adenosine could be involved. We have provided evidence that the prostanoid system plays an important role in regulation of neonatal cerebral hemodynamics under several conditions. In

Received November 30, 1987; accepted April 13, 1988.

Correspondence Massroor Pourcyrous, M.D., Newborn Center, 853 Jefferson Avenue, Room 201, Memphis, TN 38163.

Supported in part by grants in aid from the National Institutes of Health and the Tennessee Affiliate of the American Heart Association and by program project Grant NINCDS-NIA from the National Institutes of Health. C.L. was an Established Investigator of the American Heart Association. particular, in piglets cerebral vasodilation during combined arterial hypoxia and hypercapnia $(4,5)$, hemorrhagic hypotension $(6,7)$, and increase in airway pressure $(8)$ is accompanied by increased levels of prostacyclin and $\mathrm{PGE}_{2}$ in the CSF surrounding cerebral resistance vessels. Further, inhibition of prostanoid synthesis by administration of indomethacin severely blunts cerebrovascular dilation under these conditions. If prostanoids participate in cerebral vasodilation during a more severe perturbation of arterial blood gases such as accompanies asphyxia and reventilation is unclear. Allen et al. (9) found that asphyxia in neonatal guinea pigs increases brain levels of prostanoids. However, in that study, prostanoid levels in whole brain were measured, and prostanoid changes were not correlated with cerebral hemodynamics. Brain levels of prostanoids are difficult to interpret, because the bulk of whole brain tissue is cytoplasm, and prostanoids are in the extracellular fluid.

The purpose of our study was to examine the effects of asphyxia and reventilation on cerebral hemodynamics and levels of CSF prostanoids in neonatal pigs. We tested the hypothesis that cerebrovascular dilation after asphyxia is accompanied by increases in CSF levels of prostacyclin and $\mathrm{PGE}_{2}$.

\section{MATERIALS AND METHODS}

Thirteen newborn pigs (1.2-1.8 kg) of either sex, 1-5 days of age, were anesthetized with intramuscular ketamine-hydrochloride and acepromazine ( 33 and $3.3 \mathrm{mg} / \mathrm{kg}$, respectively). Six of 13 piglets were used in the asphyxia experiments and seven were used to determine the cerebrovascular responsiveness to $\mathrm{PGE}_{2}$ and $I_{2}$ (see below). A catheter was inserted into the femoral vein for injection of $\alpha$-chloralose, $50 \mathrm{mg} / \mathrm{kg}$ initially, followed by 10 $\mathrm{mg} / \mathrm{kg} / \mathrm{h}$ to maintain the desired level of anesthesia. Another catheter was inserted into the femoral artery to record blood pressure and to sample blood. The animals were intubated and ventilated with air using a Harvard piston-type ventilator.

Body temperature was maintained between 37 and $38^{\circ} \mathrm{C}$ by wrapping the piglet in plastic wrap and a water-circulated heating pad. Then, a closed cranial window (4) was implanted over the left parietal cortex so the pial arteriolar diameter could be measured and CSF sampled. To implant the cranial window, the scalp was cut and reflected from the skull. A hole approximately $2 \mathrm{~cm}$ in diameter was made on the skull. Incision was made through the dura and arachnoid membranes, and these membranes then were reflected over the edge of the bone, into which a stainless steel ring with a premounted glass coverslip was inserted. The window was cemented in place with dental acrylic. Three needles pierce the ring and allow injection of artificial CSF under the window and sampling of CSF from under the window. The space under the window was filled with artificial $\mathrm{CSF}\left(\mathrm{Na}^{+} 150 \mathrm{mEq} /\right.$ liter, $\mathrm{K}^{+} 3 \mathrm{mEq} /$ liter, $\mathrm{Ca}^{2+} 2.5 \mathrm{mEq} /$ liter, $\mathrm{Mg}^{2+} 1.2 \mathrm{mEq} / \mathrm{liter}$, $\mathrm{Cl}^{-} 132 \mathrm{mEq} /$ liter, glucose $3.7 \mathrm{mM}$, urea $6 \mathrm{mM}, \mathrm{HCO}_{3}{ }^{-} 25$ $\mathrm{mEq} / \mathrm{liter}, \mathrm{pH}=7.33, \mathrm{PCO}_{2}=46 \mathrm{~mm} \mathrm{Hg}, \mathrm{PO}_{2}=43 \mathrm{~mm} \mathrm{Hg}$ ). The volume directly below the window was approximately 500 
$\mu$ l. After the implantation of the window, $30 \mathrm{~min}$ was allowed for equilibration of CSF under the window.

Pial arterioles were observed with a Wild trinocular stereomicroscope. Pial arteriolar diameter was measured with a television camera mounted on the microscope, a videomonitor, and a video microscaler. Briefly, the image of an arteriole was displayed on the television monitor and the sides of the vessels were bracketed by parallel lines projected by the microscaler. As the arteriolar diameter changed, the lines were moved manually to correspond with the vessel walls. Precalibration of the distance between the lines allowed determination of arteriolar diameter.

\section{EXPERIMENTAL DESIGN}

The asphyxia experiment was carried out in a group of six piglets $(1.2-1.8 \mathrm{~kg})$ of either sex, $1-5$ days old. After flushing the cranial window with artificial CSF, the following baseline measurements were taken: arterial blood pressure, arterial blood gas values, and pial arteriolar diameter. Additionally, $300 \mu \mathrm{l}$ of CSF were collected from under the cranial window. CSF was collected by slowly infusing artificial CSF through one needle and allowing the CSF under the window to drip freely from another needle on the opposite side of the window. The respirator then was turned off for 4-10 min based on animal's tolerance to asphyxia and the tubing to the ventilator clamped. Pial arteriolar diameter and blood pressure were measured during asphyxia, and CSF was sampled again at the end of the asphyxia. We terminated the asphyxial period when the animals had exhibited severe bradycardia and arterial blood pressure fell to $\leq 20 \mathrm{~mm} \mathrm{Hg}$. After the respirator was turned on, measurements were repeated, and CSF sampled after 5-12 min of reventilation.

In the dose response experiment, seven piglets comparable to previous group in regard to age, sex, and weight were studied. The piglets were pretreated with indomethacin $(10 \mathrm{mg} / \mathrm{kg}$, intravenous), $30 \mathrm{~min}$ earlier in order to stop endogenous prostaglandin production. We have shown previously that this dose of indomethacin crosses the blood brain barrier in sufficient quantities to drastically reduce synthesis of brain prostaglandins in piglets (10). $\mathrm{PGE}_{2}, 200$ and $2000 \mathrm{pg} / \mathrm{ml}$ and $\mathrm{PGI}_{2}, 500$ and 1000 $\mathrm{pg} / \mathrm{ml}$ concentrations were used for this dose response experiment. To slow the degradation of $\mathrm{PGI}_{2}$ that occurs in water, this prostanoid was dissolved in (Tris)-buffer, which by itself has no effect on pial arteriolar diameter. Before application of the first prostanoid, artificial CSF with no prostanoid was injected under the window and pial arteriolar diameter was measured (control value). Then the lower concentration of the first prostanoid was topically applied and maximal diameter recorded. Increased concentration of the same prostanoid was then added and maximal diameter was again recorded. Then the artificial CSF was injected into the window two to three times, 5 min apart until the pial arteriolar diameter has returned to control value. The desired concentrations of the second prostanoid were then applied, also measuring the maximal diameter with each concentration.

Prostanoid analysis. Prostanoids (6-keto-PGF $\mathrm{PG}_{1 \alpha}$ and $\mathrm{PGE}_{2}$ ) were determined by radioimmunoassay (4). Antibodies to prostanoids were produced in rabbits immunized with prostanoids coupled to thyroglobulin using the mixed anhydride method. Cross-reactivities of our antibodies with other known biologically relevant prostanoids tested were all less than $1 \%$. The assays were performed in gelatin (Tris) buffer using the appropriate tritiated prostanoid. After $24 \mathrm{~h}$ incubation at $4^{\circ} \mathrm{C}$, the free fraction was separated from the fraction bound to antibody by precipitating the rabbit antibodies with anti-rabbit $\gamma$-globulin and $60 \%$ saturated ammonium sulfate. Data were handled by computer with determination of second order regression of free tracer over tracer bound to antibody against unlabeled prostanoids by the method of least squares. All unknowns were assayed at three dilutions with parallelism between the unknown dilution curve and the standard curve required before the result was used. Sample dilutions used in the present study allowed analysis of prostanoids concentrations between 100 and $50,000 \mathrm{pg} / \mathrm{ml}$.

Statistical analyses were carried out using Friedman analysis of variance with the different periods as repeated measure. All values are presented as mean \pm SEM.

\section{RESULTS}

During the control period, the mean arterial pressure was 57 $\pm 5 \mathrm{~mm} \mathrm{Hg}(n=6)$, and the mean arterial blood gases $(n=6)$ were: $\mathrm{pH}=7.42 \pm 0.48, \mathrm{PaCO}_{2}=32 \pm 2 \mathrm{~mm} \mathrm{Hg}$, and $\mathrm{PaO}_{2}=$ $78 \pm 4 \mathrm{~mm} \mathrm{Hg}$. During respiratory arrest, pial arterioles dilated (Fig. 1). At the end of the asphyxia period, the mean arterial $\mathrm{pH}$ was $7.17 \pm 0.94, \mathrm{PaCO}_{2}$ was $67 \pm 4 \mathrm{~mm} \mathrm{Hg}, \mathrm{PaO}_{2}$ was $7 \pm 2$ $\mathrm{mm} \mathrm{Hg}(n=3)$, and arterial pressure was $30 \pm 4 \mathrm{~mm} \mathrm{Hg}(n=$ $6)$. During reventilation, dilation was maintained, and arterial pressure returned toward control $(61 \pm 3 \mathrm{~mm} \mathrm{Hg})$. The maximal increase in pial arteriolar compared to control diameter during reventilation was about $25 \%$.

The CSF concentrations of $\mathrm{PGE}_{2}$ and 6-keto-PGF ${ }_{1 \alpha}$ during the control, asphyxia and reventilation periods are shown also in Figure 1. $\mathrm{PGE}_{2}$ did not increase significantly above control during asphyxia, but was increased $111 \pm 56 \%$ (value during asphyxia or reventilation-control value $\div$ control value $\times 100$ ) with reventilation at levels significantly higher than control. Levels of 6-keto-PGF ${ }_{1 \alpha}$ increased $111 \pm 47 \%$ with asphyxia and continued to increase further during reventilation $(244 \pm 100 \%)$.

In another group of piglets, we found that $\mathrm{PGE}_{2}$ dilated pial arterioles in the range of $200-2000 \mathrm{pg} / \mathrm{ml}$, and $\mathrm{PGI}_{2}$ dilated vessels over the range of $500-1000 \mathrm{pg} / \mathrm{ml}$ (Fig. 2). These levels were comparable to the changes in endogenous CSF levels of $\mathrm{PGE}_{2}$ and $\mathrm{PGI}_{2}$ during this experiment.

\section{DISCUSSION}

The major findings of our study in newborn pigs are that asphyxia and reventilation are accompanied by dilation of pial arterioles, and this change is associated, especially with reventilation, with a rise in CSF levels of $\mathrm{PGI}_{2}$ (represented by 6-keto$\left.\mathrm{PGF}_{1 \alpha}\right)$ and $\mathrm{PGE}_{2}$. Further, CSF levels of prostanoids during these conditions were in the vasoactive range. Thus, it appears that prostanoids contribute to the cerebrovascular dilation observed during reventilation.

Postasphyxial cerebral hyperemia has been documented in animals of different ages and species. In neonatal dogs, sheep, and pigs, $\mathrm{CBF}$ increases dramatically during reventilation after asphyxia $(1-3,11)$. For example, $\mathrm{CBF}$ increases $250 \%$ in puppies (1), $191 \%$ in lambs (3), and $167 \%$ in piglets (2). In contrast, cerebrovascular responses during asphyxia can be quite variable. Hernandez et al. (11) found that blood flow to rostral areas of the puppy fell during $5 \mathrm{~min}$ of asphyxia, whereas blood flow to the pons and medulla increased. In contrast, in preliminary studies we have found that in newborn pigs blood flow to cerebrum and brainstem increased by the first minute of asphyxia (2). However, at $6 \mathrm{~min}$ of asphyxia, blood flow to cerebrum had returned to control levels, whereas brainstem blood flow was still elevated. In our study, pial arterioles remained dilated compared to control values at the end of the asphyxial period, indicating that resistance through this segment of the cerebral circulation fell under these conditions. Examination of dilator prostanoid levels in subarachnoid CSF and pial arteriolar tone during reventilation suggests that $\mathrm{PGI}_{2}$ and $\mathrm{PGE}_{2}$ are important determinants of cerebrovascular tone under these conditions. Thus, our doseresponse curves for $\mathrm{PGI}_{2}$ and $\mathrm{PGE}_{2}$ indicate that the increase in CSF levels of these prostanoids with reventilation is sufficient to account for much but probably not all of the dilation. However, the lesser dilator response during asphyxia is probably not due to prostanoids, because the CSF levels of 6-keto-PGF ${ }_{1 \alpha}$ increase only moderately, and $\mathrm{PGE}_{2}$ levels do not increase. Other possible mediators of vasodilation under these two conditions may be 

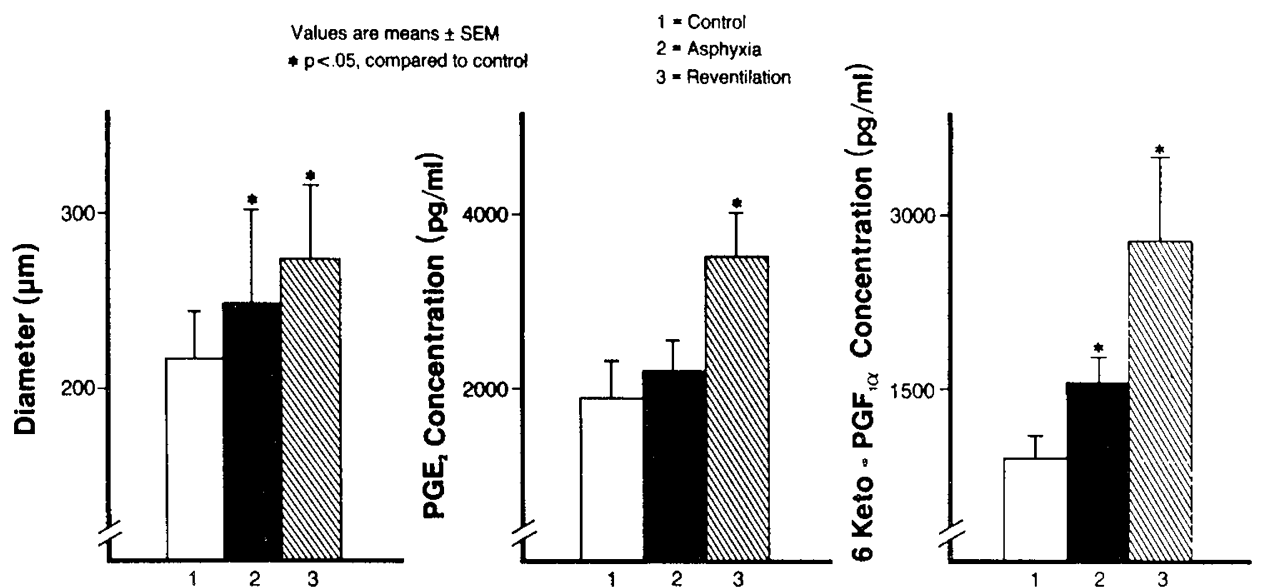

Fig. 1. Pial arteriolar diameter $(n=6)$ and $\mathrm{CSF}$ levels of $\operatorname{PGE}_{2}(n=6)$ and 6-keto- $\operatorname{PGF}_{1 \alpha}(n=4)$ during control conditions, asphyxia, and reventilation. Diameters during asphyxia, and reventilation are maximal values.
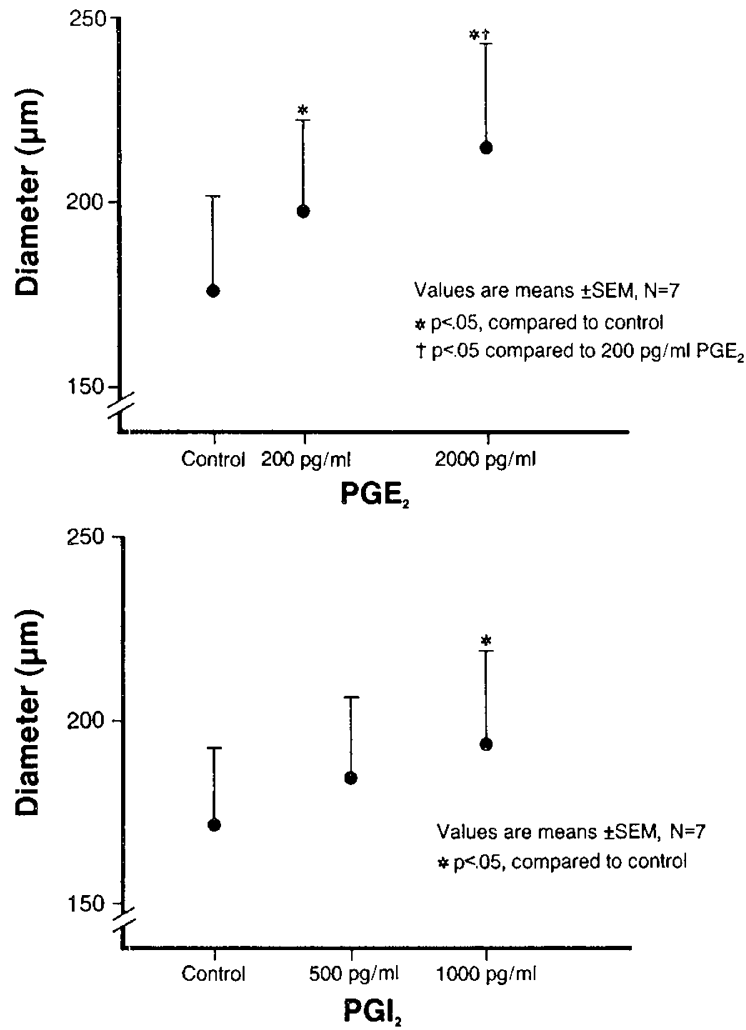

Fig. 2. Pial arteriolar responses to $\mathrm{PGE}_{2}$ and $\mathrm{PGI}_{2}$ in seven piglets.

increases in concentrations of brain adenosine $(12), \mathrm{K}^{+}(13)$, or $\mathrm{H}^{+}(14)$.

We are aware of only one other study that has examined cerebral prostanoid synthesis during asphyxia in the neonatal period. Allen et al. (9) exposed awake guinea pigs to $100 \% \mathrm{~N}_{2}$ until they stopped breathing (3-4 min). Then, some of the animals were decapitated immediately, whereas others were resuscitated and then decapitated. During asphyxia, brain levels of $\mathrm{PGE}_{2}$ but not $\mathrm{PGF}_{2 \alpha}$ were elevated over control values. After resuscitation, brain $\mathrm{PGF}_{2 \alpha}$ but not $\mathrm{PGE}_{2}$ levels were higher than control values. In those animals, arterial blood pressure, gases, and cerebral hemodynamics were not measured. These results are difficult to interpret with regard to the cerebral circulation. Prostanoids are located extracellularly and are not stored in cells. Whole brain samples contain predominantly cytoplasm, and consequently it is difficult to say if whole brain levels of prostanoids reflect the concentrations of prostanoids around cerebral resistance vessels. In our experiments, we sampled CSF from the surface of the parietal cortex where the CSF is in immediate contact with cerebral vessels. We cannot be certain that a similar relationship exists between extracellular fluid and cerebrovascular tone in other parts of the brain. However, during arterial hypoxia or hypercapnia, all cerebral resistance vessels dilate, and blood flow to all areas of the brain increases (15).

The source of prostanoids in our CSF samples was probably the underlying parietal cortex. Our experiments do not allow us to distinguish the relative contribution of other tissues, i.e. lungs, or of the cortical neurons, glial cells, and cerebral vessels to prostanoid levels in CSF. However, on the basis of evidence from other studies, 6-keto-PGF ${ }_{1 \alpha}$ most likely is derived from vessels, whereas $\mathrm{PGE}_{2}$ probably is produced by neurons or glial cells (16, 17).

In summary, cerebrovascular dilation during asphyxia and reventilation is associated with an increase in CSF levels of 6 keto-PGF ${ }_{1 \alpha}$ and $\mathrm{PGE}_{2}$. It seems likely that a major part of the vascular response during reventilation is caused by dilator prostanoids.

\section{REFERENCES}

1. McPhee AJ, Kotagal UR, Kleinman LI 1985 Cerebrovascular hemodynamics during and after recovery from acute asphyxia in the newborn dog. Pediatr Res 19:645-650

2. Pourcyrous M, Leffler C, Busija D 1987 Characteristics of prolonged cerebrovascular hyperemia following asphyxia in piglets. Pediatr Res $21: 426 \mathrm{~A}(\mathrm{abstr})$

3. Rosenberg AA 1986 Cerebral blood flow and $\mathrm{O}_{2}$ metabolism after asphyxia in neonatal lambs. Pediatr Res 20:778-782

4. Leffler CW, Busija DW 1985 Prostanoids in cortical subarachnoid cerebrospinal fluid and pial arterial diameter in newborn pigs. Circ Res 57:689-694

5. Leffler CW, Busija DW, Beasley DG, Fletcher AM, Green RS 1986 Effects of indomethacin on cardiac output distribution in normal and asphyxiated piglets. Prostaglandin 31:183-190

6. Leffler CW, Busija DW 1987 Prostanoids and pial arteriolar diameter in hypotensive newborn pigs. Am J Physiol 252:H687-H691

7. Leffler CW, Busija DW, Beasley DG, Fletcher AM 1986 Maintenance of cerebral circulation during hemorrhagic hypotension in newborn pigs: role of prostanoids. Circ Res 59:562-567

8. Mirro R, Armstead W, Busija D, Green R, Leffler C 1987 Increasing ventilation pressure increases cortical subarachnoid CSF prostanoids in newborn pigs. Pediatr Res 22:647-650

9. Allen LG, Louis TM, Kopelman AE 1982 Brain prostaglandin $E_{2}$ and $F_{2 \alpha}$ following neonatal asphyxia in the guinea pig. Biol Neonate $42: 8-14$

10. Leffler CW, Busija DW 1985 Arachidonate metabolism on the cerebral surface of newborn pigs. Prostaglandins 30:811-817

11. Hernandez MJ, Brennan RW, Hawkins RA 1980 Regional cerebral flood flow during neonatal asphyxia. In: Passonneau JV, Hawkins RA, Lust WD, Welsh FA (eds) Cerebral Metabolism and Neural Function. Williams \& Wilkins, Baltimore, pp 196-201

12. Winn HR, Rubio R, Berne RM 1981 Brain Adenosine concentration during hypoxia in rat. Am J Physiol 241:H235-H242

13. Heuser JA, Lassen NA, Nilsson B, Norberg K, Siesjo BK 1976 Evidence against $\mathrm{H}^{+}$and $\mathrm{K}^{+}$as the main factors in the regulation of cerebral blood flow during epileptic discharges, acute hypoxemia, amphetamine intoxication, and hy- 
poglycemia. A microelectrode study. In: Betz E (ed) Ionic Actions in Vascular Smooth Muscle. Springer-Verlag, Berlin, pp 110-116

14. Lassen NA 1968 Brain extracellular pH: the main factor controlling cerebral blood flow. Scand J Clin Lab Invest 22:247-251

15. Busija DW. Heistad DD 1984 Factors involved in the physiological regulation of the cerebral circulation. Rev Physiol Biochem Pharmacol 101:162-211
16. Abdel-Halim MS, Van Holst H, Meyerson B, Sachs C, Anggard E 1980 Prostaglandin profiles in tissue and blood vessels from human brain. J Neurochem 34:1331-1333

17. Heistad DD, Kontos HA 1983 Cerebral circulation. In: Shepherd JT, Abboud FM (eds) Handbook of Physiology - The Cardiovascular System IIl. American Physiology Society, Bethesda, MD, pp 137-182 